\title{
A perspectiva da Escola Austríaca sobre a concessão aeroportuária brasileira
}

\author{
Elaine Arantes $^{1, \mathrm{I}}$ (1D0000-0002-3515-8161 \\ ${ }^{1}$ Instituto Federal do Paraná (IFPR), Colombo, Paraná, Brasil
}

Otavio Ferrari Piaskowski ${ }^{2, \text { II }}$ (100000-0002-4728-5328

${ }^{2}$ Universidade Tuiuti do Paraná, Curitiba, Paraná, Brasil

\begin{abstract}
Resumo: A concessão dos aeroportos de Guarulhos, Viracopos e Brasília é discutida sob a ótica da Escola Austríaca, com base teórica na Teoria Austríaca de Processo de Mercado (KIRZNER, 1997; BARBIERI, 2001) e na Teoria Austríaca do Intervencionismo Econômico (MISES, 2010b). O problema observado é que o Estado é o poder concedente, órgão regulador e sócio na concessionária Os resultados indicam que a presença do Estado impede a eficiência da gestão empreendedora, a descoberta de novos conhecimentos e o estímulo à concorrência, já que a Empresa Brasileira de Infraestrutura Aeroportuária (INFRAERO) está presente na gestão de aeroportos concedidos e não concedidos. A INFRAERO foi negativamente impactada, pois perdeu parte da receita dos aeroportos superavitários e manteve a responsabilidade pela gestão de aeroportos deficitários ou com baixa receita. A Teoria do Intervencionismo de Ludwig von Mises, escrita na década de 1940, permanece contemporânea e orienta o processo de gestão organizacional.
\end{abstract}

Palavras-chave: Escola Austríaca, Concessão Aeroportuária; Teoria do Intervencionismo, Processo de Mercado, Regulação aeroportuária.

IPós-doutorado em Ciências Aeroespaciais (UBI-Portugal); Doutorado e Mestrado em Administração (PUC/PR); Especialização e Bacharelado em Administração (FAE). Docente EAD e presencial do IFPR. Email: elaine.arantes@ifpr.edu.br

II Pós-graduação em História Cultural com Ênfase em Antropologia (Faculdades Integradas Espírita - FIES - 2019). Licenciatura em História (Universidade Tuiuti do Paraná - UTP - 2017). Professor de História. Email: ofpias@yahoo.com.br 


\title{
The Austrian School's perspective on the Brazilian airport concession
}

\begin{abstract}
The concession of the Guarulhos, Viracopos and Brasilia airports is discussed from the perspective of the Austrian School based on the Austrian Theory of Market Process (KIRZNER, 1997; BARBIERI, 2001) and the Austrian Theory of Economic Intervention (MISES, 2010b). The problem observed is that the state is the granting authority, regulatory body and partner in the concessionaire. The results indicate that the presence of the state prevents the efficiency of entrepreneurial management, the discovery of new knowledge and the stimulation of competition. It is due to the fact that the Brazilian Airport Infrastructure Company (INFRAERO) is present in the management of airports granted and not granted. INFRAERO was negatively impacted as it lost part of its revenue from surplus airports and maintained its responsibility for managing low-income or deficit airports. Ludwig von Mises's Theory of Interventionism, written in the 1940s, remains contemporary and guides the process of organizational management.
\end{abstract}

Keywords: Austrian school, Airport Concession, Intervention Theory, Market Process; Airport Regulation.

\section{La perspectiva de la Escuela Austríaca sobre la concesión aeroportuária brasileña}

Resumen: La concesión de los aeropuertos de Guarulhos, Viracopos y Brasília se discute desde la perspectiva de la Escuela Austriaca basada en la Teoría Austriaca del Proceso de Mercado (KIRZNER, 1997; BARBIERI, 2001) y en la Teoría Austriaca de Intervención Económica (MISES, 2010b). El problema observado es que el Estado es la autoridad otorgante, el organismo regulador y el socio del concesionario. Los resultados indican que la presencia del Estado impide la eficiencia de la gestión empresarial, el descubrimiento de nuevos conocimientos y el estímulo de la competencia desde la Compañía Brasileña de Infraestructura Aeroportuaria (INFRAERO) está presente en la gestión de aeropuertos concedidos y no concedidos. INFRAERO se vio afectada negativamente, ya que perdió parte de los ingresos de los aeropuertos superavitarios y mantuvo su responsabilidad de administrar aeropuertos de bajos ingresos o con déficit. La Teoría del Intervencionismo de Ludwig von Mises, escrita en la década de 1940, sigue siendo contemporánea y guía el proceso de gestión organizacional.

Palabras clave: Escuela austríaca, Concesión aeroportuária, Teoría de intervención, Proceso de mercado, Regulación del aeropuerto. 


\section{Introdução}

Em 2011, o governo brasileiro deu início ao processo de desestatização da gestão aeroportuária brasileira promovendo a concessão de aeroportos para a iniciativa privada. Desde então, 22 aeroportos foram concedidos, em cinco rodadas, em todo o país (ANAC, 2019). A sexta rodada de concessões contempla 22 aeroportos e está prevista para o terceiro trimestre de 2020 (PPI, 2019). Di Pietro (2004) conceitua concessão como a "delegação de um serviço ou obra pública, feita pela Administração Pública para a iniciativa privada, com direito de uso que será explorado por sua conta e risco, cumprindo prazos e seguindo regras contratuais". Em sua obra, Paranaíba e Bulhões (2019, p. 27-28) estudam os investimentos feitos no Brasil no setor de transportes e citam que "um dos casos mais emblemáticos foram as obras para a realização da Copa do Mundo FIFA no Brasil em 2014" evento internacional que, somado aos Jogos Olímpicos e Paraolímpicos no Rio de Janeiro em, 2016, reforçou "o argumento de "uma oportunidade de ofertar infraestrutura para a população". Nesse contexto, se inserem as concessões aeroportuárias brasileiras. Nessa perspectiva, desenvolve-se o presente estudo, tendo como objeto de pesquisa a segunda rodada de concessão aeroportuária brasileira. Esta escolha se deu por dois motivos.

Em primeiro lugar, porque esta rodada de concessões contemplou três aeroportos estratégicos para o país: Guarulhos, Viracopos e Brasília. O aeroporto de Guarulhos, segundo a INFRAERO (2016), apresenta a maior movimentação anual de passageiros no Brasil, além de ter a maior movimentação de cargas para exportação, na última década (SIMIONATO; STAMM, 2016). O maior volume de cargas importadas nos últimos dez anos foi movimentado no aeroporto de Viracopos, conforme Simionato e Stamm (2016). Quanto ao aeroporto de Brasília, sua importância se relaciona à sua localização geoestratégica, na capital do país (SILVA; ARAÚJO SOBRINHO; FORTES, 2015). Em segundo lugar, porque o modelo adotado pelo governo brasileiro nesta primeira rodada de concessões aeroportuárias contempla uma sociedade entre o consórcio privado, com $51 \%$ do controle acionário do aeroporto e de uma empresa pública: a INFRAERO com $49 \%$ do controle do aeroporto concedido. Esta característica despertou o interesse dos pesquisadores, haja vista o conjunto de objetivos que se pretendia alcançar com a concessão no setor aeroportuário brasileiro.

Os objetivos estratégicos definidos para a concessão aeroportuária foram: agilizar os investimentos por meio da gestão da iniciativa privada, que não é regida pelas normas da Lei 8.666/1993 (BRASIL, 1993), que rege o processo licitatório brasileiro; reduzir o déficit no setor aeroportuário brasileiro; atrair novos modelos de gestão, tanto gerenciais como tecnológicos; Compartilhar experiências com a INFRAERO, promovendo seu aprimoramento; e estimular a concorrência entre os aeroportos brasileiros (TCU, 2014).

O arcabouço teórico, que oferece suporte para a realização desta pesquisa, fundamenta-se nos preceitos da Escola Austríaca. Esta base teórica foi escolhida porque a Escola Austríaca "tem procurado avançar nos debates teóricos contemporâneos e na utilização de sua abordagem singular a problemas aplicados" (ANGELI, 2018, p. 681). São duas as teorias que oferecem suporte para esta pesquisa: a Teoria de Processo de Mercado, desenvolvida por Kirzner (1997) e Barbieri (2001), e a Teoria Austríaca do Intervencionismo Econômico, desenvolvida por Mises (2010b). Kirzner (1997, p. 69) formula a sua ideia de processo de mercado, a partir das ideias 
de Mises e Hayek, construindo-a em cima de três pilares: "(a) o papel do empreendedor; (b) o papel da descoberta; (c) competição sujeito à rivalidade". A novidade que Barbieri (2001) traz para esta teoria está calcada no uso das teorias do conhecimento de Friedrich Hayek para o assunto, em conjunto com temas da filosofia da ciência de Karl Popper que, em seu trabalho, assume uma postura evolucionária. Para Mises (2010b), o intervencionismo é uma terceira via entre o sistema capitalista, definido a partir da existência da propriedade privada dos meios de produção, e o sistema socialista, no qual os meios de produção são administrados pelo Estado.

Considerando-se a necessidade de investimentos para o setor aeroportuário brasileiro e a restrição orçamentária da Administração Pública brasileira, verifica-se que há um problema na modelagem do processo de concessão com a presença de uma empresa pública na sociedade com a iniciativa privada. Esta modelagem repercute tanto no contrato firmado entre a Agência Nacional de Aviação Civil (ANAC), como representante da União, e a concessionária, como também na regulação do setor. Neste trabalho, para o conceito de modelagem, adota-se a definição que Carrasco, Joaquim e Melo (2014), que apresentam para o termo em inglês design de uma concessão. Modelagem (ou design), nesta pesquisa, é considerada como "uma agência governamental [que] precisa contratar uma empresa, para prover um determinado serviço de infraestrutura" (CARRASCO; JOAQUIM; MELO, 2014, p. 22-23). No caso brasileiro, na segunda e terceira rodada, o Estado está presente em todas as partes do contrato assinado com a concessionária para a concessão. Por meio da ANAC, o Estado define as regras contratuais, regula os procedimentos e monitora as atividades da concessionária vencedora do certame. Além disso, o Estado, por meio da INFRAERO, é sócio da iniciativa privada, na concessionária. A INFRAERO detém $49 \%$ do controle acionário, enquanto que a iniciativa privada detém $51 \%$ da concessionária vencedora do certame. Diante deste problema, esta pesquisa parte do seguinte pressuposto: se o objetivo da concessão aeroportuária era atrair investimentos privados para reduzir o déficit da infraestrutura aeroportuária brasileira, por meio de investimentos feitos pelo setor privado, então teria sido coerente ter privatizado integralmente os aeroportos, ao invés de estabelecer uma sociedade público-privada para a concessionária.

Diante deste cenário, e considerando as premissas estabelecidas por Kirzner (1997) para o processo de mercado, a pergunta que esta pesquisa se propõe responder é: a gestão empreendedora necessária para descoberta de novos conhecimentos para o setor aeroportuário brasileiro, atraindo investidores para o país e estimulando a competição que leva à rivalidade, não seria mais bem estruturada integralmente pela gestão privada sem o intervencionismo estatal? Para responder esta pergunta, definiu-se como objetivo geral da pesquisa: examinar o processo de mercado constituído pela concessão aeroportuária brasileira em sua segunda rodada do ponto de vista da gestão empreendedora, da descoberta de novos conhecimentos e do estímulo à competição que leva à rivalidade. Para oferecer suporte ao alcance deste objetivo, foram estabelecidos os seguintes objetivos específicos: 1) identificar a visão austríaca para o processo de mercado, com base na gestão empreendedora, na descoberta de novos conhecimentos e na competição; 2) identificar a visão austríaca para o intervencionismo estatal, em um processo de mercado; 3) Discutir o processo de concessão à luz da Escola Austríaca, considerando as teorias escolhidas e as pesquisas contemporâneas sobre a desestatização no setor aeroportuário. 
Foi realizada uma pesquisa qualitativa, com base em um estudo exploratório fundamentado em pesquisa bibliográfica de natureza aplicada. Esta pesquisa tem relevância teórica, empírica e acadêmica. Sua relevância teórica se dá na medida em que aprofunda a discussão sobre o pensamento da Escola Austríaca, voltado para a função empresarial e para o processo de mercado. Empiricamente, esta pesquisa se justifica pela contemporaneidade do tema, pois se insere no contexto de reformas que o governo brasileiro vem propondo e realizando recentemente, em diferentes segmentos. Para os pesquisadores, o trabalho aqui realizado apresenta subsídios para novos estudos relativos à desestatização no Brasil, seja na infraestrutura ou em outros setores.

Este artigo é composto de uma introdução que contextualiza o tema e sua delimitação, apresenta o problema verificado e os objetivos que a pesquisa pretende alcançar e o arcabouço teórico utilizado para as análises. Na sequência, serão apresentados os seguintes capítulos: a Fundamentação teórica que aprofunda as teorias selecionadas para explicar o caso e possibilitar sua análise; os Procedimentos metodológicos adotados para o desenvolvimento da pesquisa; a Apresentação e análise dos dados coletados feita pelos pesquisadores à luz das teorias pré-estabelecidas; e por fim, as Considerações finais elaboradas pelos pesquisadores. Para oferecer subsídios para que futuras pesquisas sejam realizadas, este trabalho finaliza com a apresentação das Referências bibliográficas, utilizadas para o desenvolvimento do estudo.

\section{Fundamentação teórica}

Considerando o problema apresentado e os objetivos definidos para esta pesquisa, apresentam-se, neste capítulo, as duas teorias da Escola Austríaca que oferecem suporte para as análises pretendidas: a Teoria de Processo de Mercado, desenvolvida por Kirzner (1997) e Barbieri (2001), e a Teoria Austríaca do Intervencionismo Econômico, desenvolvida por Mises (2010b). A partir das ideias de Mises e Hayek, Kirzner (1997) formula a sua ideia de processo de mercado, construída em cima de três pilares: “(a) o papel do empreendedor; (b) o papel da descoberta; (c) competição sujeito à rivalidade.".

Com relação ao primeiro pilar, "papel do empreendedor", retoma-se a visão de Ludwig von Mises, notando que o processo de mercado é um processo, acima de tudo, "especulativo", em que, para o empreendedor, características como "criatividade", "coragem" e "esforço" possuem importância fundamental (KIRZNER, 1997, p. 69-70). O segundo pilar, o "papel da descoberta" é observado uma vez que, ao longo do processo de mercado, há um aumento generalizado da informação e do conhecimento acerca do planejamento dos outros agentes. Dessa forma, erros podem ser corrigidos e eliminados, enquanto os planos acertados recebem o prêmio por eles, na forma de "lucros puros" (1997, p. 70). Com este pilar, Kirzner retoma a definição de Hayek sobre os preços, como estabelecidos em um "sistema", em que os planos e atividades dos agentes econômicos são constantemente ajustados e alterados pela mudança desses preços (2010, p. 70).

\footnotetext{
${ }^{1}$ Tradução do original: "(a) the entrepreneurial role; (b) the role of discovery; (c) rivalrous competition".
} 
Uma característica da atividade empreendedora é o conceito de "estado de alerta", definido pelo autor como sendo "uma atitude de percepção de oportunidades [de lucro] disponíveis (mas até aquele momento despercebidas)"” (KIRZNER, 1997, p. 72). Assim, pode-se resumir o empreendedor como uma pessoa realizando uma busca contínua e ativa, por novas oportunidades de lucro, inexistentes até a sua percepção. Uma consequência deste segundo pilar é que, com o aumento do conhecimento dos agentes acerca dos planos de outros agentes no mercado, surge um tratamento distintamente austríaco do equilíbrio, porém, distinto do equilíbrio perfeito e completo por parte dos neoclássicos. Posto de outra forma, o processo de mercado seria um processo "equilibrador", mas nunca "equilibrado". Neste sentido, os

Austríacos, porém, são cuidadosos ao insistir (I) que a contínua alteração nos gostos, disponibilidade dos recursos e conhecidas possibilidades técnicas sempre impedem este processo de chegar perto de sua conclusão; e (II) que a coragem e imaginação empreendedora podem levar a perdas empreendedoras puras assim como lucros puros $^{3}$. (KIRZNER, 1997, p. 72)

O terceiro pilar, sobre o qual Kirzner constrói sua teoria de processos de mercado, é o conceito de "competição sujeita à rivalidade". Nele, observa-se que o conjunto de empreendedores não é um conjunto unido, mas formado a partir da rivalidade, ou seja, através da competição dos distintos "estados de alerta" e perseguição implacável do lucro econômico, servindo à população em geral (1997, p. 73). A partir desses três pilares, pode-se concluir que o processo de mercado, para Kirzner (1997), é marcado, ao contrário da perspectiva estática do neoclassicismo, por um intenso dinamismo, com constantes mudanças, em que os empresários possuem papel central, através da rivalidade e da postura sempre alerta para oportunidades inexploradas de lucro. Outra teoria austríaca sobre os processos de mercado é desenvolvida por Barbieri (2001), que, além de realizar um histórico dos debates sobre este tema entre Israel Kirzner, Ludwig Lachmann e Murray Rothbard, promove novas discussões teóricas acerca deste tema, que auxiliam na compreensão do processo de mercado para a Escola Austríaca Moderna, e seus usos para a análise da concessão aeroportuária no Brasil, tema deste artigo. O primeiro fator, para a teoria de processo de mercado de Barbieri (2001), é reafirmar a observação de Friedrich Hayek de que o mercado e seu estudo podem ser apenas compreendidos quando se tem em mente "o estudo do crescimento do conhecimento dos agentes" (2001, p. 164). Além disso, ele reafirma também o centro da filosofia da ciência popperiana, que é o "falseacionismo" e o "racionalismo crítico", ou seja, a noção de que a ciência evolui, a partir de testes de teorias distintas e da crítica destas teorias (BARBIERI; FEIJÓ, 2013).

Assim, o empreendedor, em conjunto com o estado de alerta e a coragem encontradas em Kirzner (1997), realiza, consciente ou inconscientemente, um elaborado processo de testes, semelhantes à ciência popperiana. Em tais testes, ele observa, por exemplo, se devem lançar novos produtos no mercado, como deve realizar o marketing desses produtos, observar a qualidade e os defeitos dos produtos e a situação presente do mercado. A partir desses testes,

\footnotetext{
${ }^{2}$ Tradução do Original: "[...] attitude of receptiveness to available (but hitherto overlooked) opportunities".

${ }^{3}$ Tradução do Original: "Austrians are careful to insist (i) that continual change in tastes, resource availabilities, and known technological possibilities always prevent this equilibrative process from proceeding anywhere near to completion; and (ii) that entrepreneurial boldness and imagination can lead to pure entrepreneurial losses as well as to pure profit".
} 
o empresário pode decidir executar, alterar ou mesmo abandonar seu plano, de acordo com sua percepção de que terá ou não lucros com sua atividade (BARBIERI, 2001, p. 165-166). Um segundo fator, na teoria de Barbieri (2001), é a associação entre as teorias de Hayek e Popper e a sua aplicação ao processo de mercado. Com essas duas teorias, ele chega à conclusão de que o mercado funciona de maneira análoga ao processo evolutivo. Em tal processo, combinam-se dois elementos: a seleção de planos acertados por parte de alguns empresários, com a evolução do conhecimento a partir desta seleção. Nota-se que, nesta seleção, não se postula para onde irá este processo, uma vez que este é imprevisível (BARBIERI, 2001, p. 168-172).

Tendo estes dois fatores em mãos, pode-se resumir que o mercado, para Barbieri (2001), é um processo de epistemologia evolucionária. Ou seja, ele é composto de um processo epistemológico, pois o empresário formula planos de ação e submete estes a testes no mercado, com o objetivo de obter lucro. Porém, por ser também um processo evolutivo, tais testes podem ser frutíferos ou não, uma vez que existe no mercado o importante elemento do sistema de preços ou, em outras palavras, o mecanismo de lucros e perdas. Desta forma, ocorre neste processo uma eliminação dos planos mal formulados e uma premiação dos planos acertados. Resumidamente, o processo de mercado, tanto em Kirzner (1997), quanto em Barbieri (2001), é um sistema espontâneo já que não segue um plano único, racionalmente planejado como é no socialismo, nem irracionalmente organizado, nem um "método anárquico de produção" como se acredita ser o capitalismo (MISES, 2012 p. 30). Mises (2010a, p. 28) define o intervencionismo como um "sistema de economia de mercado obstruída". Assim, a intervenção do Estado pode ser definida como:

Uma ordem isolada emitida pela autoridade que representa o aparato de poder; obriga o empresário e o proprietário dos meios de produção a empregar esses meios de uma maneira diferente da que empregariam se agissem pelo que lhes determina o mercado (MISES, 2010a, p. 28).

No presente trabalho de pesquisa, considera-se o intervencionismo estatal como a atuação do Estado em todas as partes que celebraram o contrato de concessão, ou seja: o poder concedente, representado pela ANAC em nome da União que é também o agente regulador do setor, e a parte sócia da iniciativa privada, representada pela INFRAERO. A partir destas reflexões, perguntas relativas ao processo de mercado são trazidas para a discussão. São elas: "Podem essas medidas fazer com que o governo consiga atingir os objetivos que deseja? ou será que essas intervenções produzirão resultados que, do próprio ponto de vista do governo, são ainda menos desejáveis do que os que seriam obtidos pelo livre funcionamento do mercado que ele está tentando modificar?" MISES (2010a, p. 29). Complementando o conceito de intervencionismo, tem-se que aquilo que o caracteriza

É o fato de que o governo não limita suas atividades à preservação da propriedade privada dos meios de produção e à proteção contra as tentativas de violência ou fraude; o governo interfere na atividade econômica através de ordens e proibições (MISES, 2010a, p. 817-818).

Nesta pesquisa, considera-se o intervencionismo estatal como a atuação do Estado em todas as partes que celebraram o contrato de concessão, ou seja: o poder concedente representado pela ANAC em nome da União que é também o agente regulador do setor e 
a parte sócia da iniciativa privada representada pela INFRAERO. A partir destas reflexões, perguntas elaboradas por Mises (2010a), relativas ao processo de mercado, são trazidas para a discussão. São elas: "Podem essas medidas fazer com que o governo consiga atingir os objetivos que deseja? Ou será que essas intervenções produzirão resultados que, do próprio ponto de vista do governo, são ainda menos desejáveis do que os que seriam obtidos pelo livre funcionamento do mercado, que ele está tentando modificar?" (MISES, 2010b, p. 29).

\section{Procedimentos metodológicos}

Foi realizada pesquisa qualitativa com base em um estudo exploratório, fundamentado em pesquisa bibliográfica de natureza aplicada. O Quadro 1 apresenta o esquema conceitual, que representa o fio condutor deste trabalho, associando os objetivos estratégicos da concessão aeroportuária à fundamentação teórica definida, permitindo a definição das categorias de análise, que serão retomadas mais adiante neste relato.

Estuda-se a concessão aeroportuária brasileira em sua segunda rodada, contemplando os aeroportos de Guarulhos, Viracopos e Brasília. Cooper e Schildler (2003) orientam que a pesquisa exploratória permite o aprimoramento das ideias acerca de um tema, bem como possibilita descobrir intuições que guiarão o pesquisador no desenvolvimento do estudo.

Quadro 1. Esquema conceitual da pesquisa

\begin{tabular}{|c|c|c|c|c|}
\hline $\begin{array}{l}\text { Sob o } \\
\text { intervencionismo, } \\
\text { Mises (2010b) } \\
\text { questiona: }\end{array}$ & $\begin{array}{l}\text { Objetivos da } \\
\text { concessão } \\
\text { aeroportuária } \\
\text { conforme } \\
\text { TCU (2014) }\end{array}$ & $\begin{array}{l}\text { Categorias } \\
\text { de análise } \\
\text { conforme } \\
\text { Kirzner (1997) }\end{array}$ & \multicolumn{2}{|c|}{$\begin{array}{l}\text { Concepções teóricas da Escola Austríaca } \\
\text { sobre processo de mercado }\end{array}$} \\
\hline $\begin{array}{l}\text { Podem essas } \\
\text { medidas fazer } \\
\text { com que o governo } \\
\text { consiga atingir } \\
\text { os objetivos que } \\
\text { deseja? ou será que } \\
\text { essas intervenções } \\
\text { produzirão } \\
\text { resultados que, } \\
\text { do próprio } \\
\text { ponto de vista } \\
\text { do governo, são } \\
\text { ainda menos } \\
\text { desejáveis do que } \\
\text { os que seriam } \\
\text { obtidos pelo livre } \\
\text { funcionamento } \\
\text { do mercado que } \\
\text { ele está tentando } \\
\text { modificar? } \\
\text { MISES } \\
\text { (2010b, p. 29) }\end{array}$ & $\begin{array}{l}\text { Compartilhar } \\
\text { experiências com } \\
\text { a INFRAERO } \\
\text { promovendo seu } \\
\text { aprimoramento; } \\
\text { Atrair novos modelos } \\
\text { de gestão tanto } \\
\text { gerenciais como } \\
\text { tecnológicos. }\end{array}$ & $\begin{array}{l}\text { Descoberta } \\
\text { de novos } \\
\text { conhecimentos }\end{array}$ & $\begin{array}{l}\text { O empreendedor tem } \\
\text { características como "criatividade, } \\
\text { coragem e esforço" (KIRZNER, } \\
\text { 1997, p. 69-70). Empreendedor está } \\
\text { continuamente em busca de novas } \\
\text { oportunidades de lucro } \\
\text { (KIRZNER, 1997). } \\
\text { No processo de mercado, planos } \\
\text { e atividades são continuamente } \\
\text { ajustados devido ao aumento } \\
\text { contínuo de informação e } \\
\text { conhecimento. O empreendedor } \\
\text { está sempre atento a novas } \\
\text { oportunidades. } \\
\text { (KIRZNER, 1997) }\end{array}$ & $\begin{array}{l}\text { O mercado } \\
\text { funciona de } \\
\text { maneira análoga } \\
\text { ao processo } \\
\text { evolutivo. } \\
\text { Em tal processo, } \\
\text { combinam-se } \\
\text { dois elementos: a } \\
\text { seleção de planos } \\
\text { acertados por } \\
\text { parte de alguns } \\
\text { empresários com } \\
\text { a evolução do } \\
\text { conhecimento } \\
\text { a partir } \\
\text { desta seleção } \\
\text { (BARBIERI, 2001). }\end{array}$ \\
\hline
\end{tabular}

Fonte: Elaboração dos autores. 
Com planejamento flexível, a pesquisa exploratória envolve um levantamento bibliográfico que permite a coleta de dados secundários para sustentar a análise e a discussão do tema proposto. Lakatos e Marconi (2010) sinalizam que a pesquisa bibliográfica se compõe de publicações em geral, já feitas por outros pesquisadores. Para a realização do presente trabalho, foram coletados dados secundários, que se encontram à disposição na internet, bem como em relatórios publicados pela INFRAERO, Tribunal de Contas da União (TCU), ANAC e pelo Programa de Parcerias de Investimentos (PPI). As plataformas Scopus e Web of Science foram consultadas, para se levantar artigos científicos publicados por pesquisadores brasileiros e internacionais, abordando o tema da desestatização aeroportuária em outros países.

A análise dos dados levantados será apresentada em capítulo específico, obedecendo a seguinte ordem: parte-se dos questionamentos feitos por Mises (2010a) a partir de sua Teoria sobre o Intervencionismo, confrontando-os com os objetivos estratégicos da concessão segundo TCU (2014), as categorias de análise conforme Kirzner (1997) e Barbieri (2001), e com os resultados de pesquisas realizadas, por outros autores, sobre a desestatização aeroportuária em outros países. A natureza aplicada da pesquisa se justifica por ser o objeto de estudo um processo iniciado no Brasil, no setor aeroportuário brasileiro, que continua sendo foco da atenção da gestão pública e da gestão privada brasileira.

\section{Apresentação e análise dos dados}

Neste capítulo, apresenta-se inicialmente o objeto de estudo escolhido. Na sequência, são trazidos os dados secundários coletados, analisando-os à luz das teorias do processo de mercado (KIRZNER, 1997; BARBIERI, 2001) e do intervencionismo (MISES, 2010a). Confronta-se esta análise com os resultados de pesquisas feitas por estudiosos do tema da desestatização de aeroportos ocorrida em outros países.

\subsection{Apresentação do objeto de estudo: A concessão aeroportuária brasileira}

O objeto de estudo deste trabalho de pesquisa é a segunda rodada de concessão aeroportuária, realizada no Brasil. Para se compreender o contexto em que se insere este processo, apresentam-se as concessões já realizadas e os processos previstos para 2020. No Quadro 2, estão resumidas as cinco rodadas de concessões já realizadas no setor aeroportuário brasileiro contemplando 22 aeroportos. Vale ressaltar que, na primeira rodada, por se tratar da construção de um aeroporto completamente novo, a obra foi entregue integralmente para a Corporación América S/A (INFRAMÉRICA), vencedora do leilão. Na segunda e terceira rodada, a modelagem adotada, e que é tratada neste trabalho de pesquisa, contempla a gestão do negócio aeroportuário, por uma sociedade entre o consórcio privado e uma empresa pública, a INFRAERO. A modelagem foi alterada na quarta rodada, com a saída da INFRAERO dando lugar a uma empresa privada, firmando contrato com a União representada pela ANAC. 
Quadro 2. Aeroportos brasileiros concedidos de 2011 a 2019

\begin{tabular}{|c|c|c|c|c|}
\hline & $\begin{array}{l}\text { Assinatura do contrato } \\
\text { /Início da concessão }\end{array}$ & $\begin{array}{l}\text { Prazo da } \\
\text { concessão }\end{array}$ & Aeroportos concedidos & Observação \\
\hline $\begin{array}{l}\text { Assinatura } \\
\text { do contrato }\end{array}$ & 28/11/2011 & 28 anos & $\begin{array}{l}\text { São Gonçalo do Amarante } \\
\text { (ASGA), Natal/RN }\end{array}$ & $\begin{array}{l}\text { Primeira } \\
\text { rodada }\end{array}$ \\
\hline \multirow{5}{*}{$\begin{array}{l}\text { Início da } \\
\text { concessão }\end{array}$} & $11 / 07 / 2012$ & 20 anos & Guarulhos/SP & \multirow{3}{*}{$\begin{array}{l}\text { Segunda } \\
\text { rodada }\end{array}$} \\
\hline & $11 / 07 / 2012$ & 30 anos & Viracopos/SP & \\
\hline & $24 / 07 / 2012$ & 25 anos & Brasília/DF & \\
\hline & 07/05/2014 & 25 anos & Galeão/RJ & \multirow{2}{*}{$\begin{array}{l}\text { Terceira } \\
\text { rodada }\end{array}$} \\
\hline & 07/05/2014 & 30 anos & Confins/MG & \\
\hline \multirow{5}{*}{$\begin{array}{l}\text { Assinatura } \\
\text { do contrato }\end{array}$} & 28/07/2017 & 30 anos & $\begin{array}{c}\text { Florianópolis/SC, Fortaleza/CE, } \\
\text { Salvador/BA }\end{array}$ & \multirow{2}{*}{$\begin{array}{l}\text { Quarta } \\
\text { rodada }\end{array}$} \\
\hline & $28 / 07 / 2017$ & 25 anos & Porto Alegre/RS & \\
\hline & 03/09/2019 & 30 anos & $\begin{array}{c}\text { Cuiabá, Sinop, Rondonópolis e Alta } \\
\text { Floresta (Mato Grosso) }\end{array}$ & \multirow{3}{*}{$\begin{array}{l}\text { Quinta } \\
\text { rodada }\end{array}$} \\
\hline & 05/09/2019 & 30 anos & $\begin{array}{c}\text { Recife/PE, Maceió/AL, João Pessoa/PB, } \\
\text { Aracaju/SE, Campina Grande/PB } \\
\text { e Juazeiro do Norte/CE }\end{array}$ & \\
\hline & 05/09/2019 & 30 anos & Vitória/ES e Macaé/RJ & \\
\hline
\end{tabular}

Fonte: Elaboração dos autores com base em ANAC (2019).

Conforme o Programa de Parcerias de Investimentos (PPI) (2019), estão previstas para o ano de 2020 as concessões de mais 22 aeroportos em todo país, conforme se resume no Quadro 3.

Até o momento, 43 aeroportos integram os processos de concessão aeroportuária no país tanto nas operações já realizadas quanto na previsão para 2020. A continuidade deste processo reforça a importância da pesquisa aqui realizada, que estimula a reflexão e a discussão sobre a modelagem a ser adotada, não somente no setor aeroportuário, mas também em outros setores, no Brasil.

Quadro 3. Concessões aeroportuárias previstas para 2020

\begin{tabular}{|c|c|c|c|c|c|}
\hline \multicolumn{6}{|c|}{ Prazo da concessão: 30 anos } \\
\hline Bloco Nor & & Bloco & & Bloco Su & \\
\hline Aeroporto & Estado & Aeroporto & Estado & Aeroporto & Estado \\
\hline Manaus & & Goiânia & Goiás & Londrina & \\
\hline $\begin{array}{l}\text { Tabatinga } \\
\text { Tefé }\end{array}$ & Amazonas & $\begin{array}{l}\text { São Luís } \\
\text { Imperatriz }\end{array}$ & Maranhão & $\begin{array}{l}\text { Curitiba } \\
\text { Bacacheri }\end{array}$ & Paraná \\
\hline Porto Velho & Rondônia & Teresina & Piauí & $\begin{array}{l}\text { Foz do Iguaçu } \\
\text { Navegantes }\end{array}$ & \\
\hline $\begin{array}{l}\text { Rio Branco } \\
\text { Cruzeiro do Sul }\end{array}$ & Acre & Palmas & Tocantins & $\begin{array}{l}\text { Joinville } \\
\text { Pelotas }\end{array}$ & Santa Catarina \\
\hline Boa Vista & Roraima & Petrolina & Pernambuco & $\begin{array}{l}\text { Uruguaiana } \\
\text { Bagé }\end{array}$ & $\begin{array}{l}\text { Rio Grande do } \\
\text { Sul }\end{array}$ \\
\hline
\end{tabular}

Fonte: Elaboração dos autores com base em PPI (2019). 


\subsection{Análise e discussão dos dados coletados à luz das teorias austríacas e de resultados de outros estudos}

Conforme já apresentado anteriormente, as análises se iniciam pelos seguintes questionamentos, feitos por Mises (2010a) em sua obra abordando a Teoria do Intervencionismo, quando aborda a intervenção estatal:

"Podem essas medidas fazer com que o governo consiga atingir os objetivos que deseja? Ou será que essas intervenções produzirão resultados que, do próprio ponto de vista do governo, são ainda menos desejáveis do que os que seriam obtidos pelo livre funcionamento do mercado que ele está tentando modificar?" (MISES, 2010b, p. 29).

A presença da INFRAERO na sociedade com a iniciativa privada, para constituir a concessionária vencedora do leilão, traz consigo as amarras da Lei 8666/1993. Isso compromete o alcance dos objetivos de agilizar investimentos e reduzir o déficit no setor. Um exemplo disso é a obrigatoriedade de execução, nos aeroportos, de obras por parte da INFRAERO, conforme estabelecido no contrato de concessão. Caso a INFRAERO

Não celebre os contratos sob sua responsabilidade no prazo fixado, a Concessionária poderá, para garantir o cumprimento do Contrato de Concessão, contratar a obra ou serviço listado no Anexo 3 - Obras do Poder Público no mercado, observadas as disposições da Lei no 8666/1993 [...]. (ANAC 2012, cap. 2, seção VII, cláusula 2.47, p. 20)

A concessionária (na qual a própria INFRAERO é sócia) pode efetuar estas obras nos aeroportos e pode ainda ser ressarcida por este investimento, mas de acordo com uma tabela previamente estabelecida pela ANAC e definida em contrato. Assim sendo, a concessionária somente fará as obras que forem imprescindíveis para a operação aeroportuária. As receitas aeroportuárias são utilizadas para estes investimentos, assim como para sustentar a operação do negócio e para pagar a outorga relativa aos lances vencedores do leilão. Para que se tenha uma ideia dos valores de outorga, apresenta-se o Quadro 4, relativa à segunda rodada, objeto de estudo desta pesquisa.

O exercício da criatividade, coragem e esforço (KIRZNER, 1997), por parte da iniciativa privada sócia da concessionária, ficam comprometidos na medida em que a sócia é uma empresa pública e, por mais que seja minoritária, ainda contribui com uma parcela importante de $49 \%$ na sociedade. Com relação ao compartilhamento de experiências, modelos de gestão e tecnologias com a INFRAERO, a realidade após as concessões indica que a referida empresa pública se viu diante de uma situação delicada. Os aeroportos mais rentáveis foram concedidos e a INFRAERO ainda permanecia com a gestão de aeroportos deficitários e com uma folha de pagamento que não poderia ser reduzida face às diretrizes estabelecidas pela Lei 8.112/1990 (BRASIL, 1990). Esta é uma das situações, ocorridas devido à intervenção estatal, conforme questiona Mises (2010a). Pelo mesmo motivo fica também limitada a evolução da ação da concessionária conforme orienta Barbieri (2001). 
Quadro 4. Consórcios vencedores e outorgas para a segunda rodada de concessões aeroportuárias brasileiras

\begin{tabular}{lcccc}
\hline Aeroporto & $\begin{array}{c}\text { Lance } \\
\text { mínimo (R\$) }\end{array}$ & $\begin{array}{c}\text { Lance } \\
\text { vencedor (R\$) }\end{array}$ & Ágio & Composição do consórcio vencedor \\
\hline Guarulhos (SP) & 3,424 bilhões & 16,213 bilhões & $373 \%$ & $\begin{array}{c}\text { Invepar Investimentos e Participações } \\
\text { em Infraestrutura S/A (90\%) e }\end{array}$ \\
Viracopos (SP) & 1,471 bilhão & 3,821 bilhões & $160 \%$ & $\begin{array}{c}\text { Airports Company South Africa (ACSA) (10\%) } \\
\text { Triunfo Participações e Investimentos (45\%); } \\
\text { UTC Participações (45\%) e }\end{array}$ \\
Brasília (DF) & 582 milhões & 4,5 bilhões & $673 \%$ & $\begin{array}{c}\text { Egis Airport Operation - França (10\%) } \\
\text { Infravix Participações S/A (50\%) e } \\
\text { Corporation America S/A - Argentina (50\%) }\end{array}$ \\
\hline
\end{tabular}

Fonte: Elaboração dos autores com base em ANAC (2019).

O estímulo à concorrência entre aeroportos concedidos e não concedidos, que é um dos objetivos estratégicos da concessão, fica comprometido uma vez que a mesma empresa encontra-se presente nos dois grupos. Este cenário contradiz o que preconiza Kirzner (1997), quando se refere à possibilidade da rivalidade entre concorrentes. A presença da INFRAERO, como sócia da concessionária, corrobora os estudos de Graham (2011), pois compromete a eficiência ao promover a permanência do Estado, na gestão de um ativo que, conforme objetivo da concessão deveria atrair o financiamento privado, ao invés de continuar comprometendo orçamento público.

A presença da empresa estatal, como sócia do consórcio privado, corrobora a concepção ideológica do governo que idealizou e implantou o processo, uma vez que não permite que a iniciativa privada seja integralmente a gestora de um bem público. Para Graham (2011), a ideologia, que rege a gestão governamental, tem grande impacto no aumento ou na diminuição do controle estatal. Isto que acaba por comprometer a eficiência no setor, devido à falta de conhecimento de gestão aeroportuária pelo poder público.

Contrariando a lógica da desestatização no setor aeroportuário, Oum, Yan e Yu (2006; 2008), assim como Scotti et al. (2012), afirmam que a operação feita pelo setor público é mais eficiente. Mantin (2012) reforça esta afirmação, ao salientar que não somente a gestão, mas a propriedade do aeroporto deve ser pública para maximizar o bem-estar dos consumidores. Por outro lado, Graham (2011) acredita que há melhorias na eficiência e no desempenho de aeroportos privatizados, além de apresentar benefícios financeiros para a gestão pública. Além disso, reforça que a regulação se faz necessária para compensar o que chama de abuso do poder de mercado.

Gillen (2011) traz a importância da desregulação no setor aeroportuário para permitir a liberdade de escolha dos consumidores sobre as companhias aéreas que ofertam seus serviços. Reforça que as estruturas de governança são fator chave para minimizar custos e maximizar benefícios. Uma legislação robusta e a formatação adequada de um contrato de concessão são fundamentais para resultados positivos na gestão aeroportuário, do ponto de vista de Harisankar e Sreeparvathgy (2013), que reforçam, por outro lado, que políticas regulatórias devem ser adequadas para cada segmento. Para eles, soluções amigáveis com a participação 
de especialistas para cada caso são mais eficientes, do que processos regulatórios geridos pelo poder público.

Com relação ao benefício que tem o consumidor final, sem a intervenção estatal no setor aeroportuário, Paranaíba e Bulhões (2019, p. 99) reforçam que “a diminuição da participação do Estado aumentou o acesso da população a esse meio de transporte, diminuindo seu preço final". Sobre a regulação, Pereira Neto et al. (2016) orientam que, para o alcance dos objetivos da regulação, é preciso que se considere a competição no setor aeroportuário, para então se desenhar o processo regulatório. No caso brasileiro, dada a ausência de competição face à presença da INFRAERO na gestão do setor, ficaria então inviabilizado, segundo Pereira Neto et al. (2016), o desenho do processo regulatório.

\section{Considerações finais}

Para atingir o objetivo deste trabalho, foi examinado o processo de mercado constituído pela concessão aeroportuária brasileira, em sua segunda rodada, do ponto de vista da gestão empreendedora, da descoberta de novos conhecimentos e do estímulo à competição que leva à rivalidade. Foram atingidos os objetivos específicos, uma vez que foram identificadas as teorias austríacas do processo de mercado e do intervencionismo, apresentando-se seus principais conceitos. Discutiu-se também o processo de concessão à luz da Escola Austríaca, considerando as teorias escolhidas e as pesquisas contemporâneas sobre a desestatização no setor aeroportuário.

Partindo-se dos questionamentos feitos por Mises (2010a), considerados na análise do processo de concessão aeroportuária brasileira, podem-se tecer considerações sobre os pilares do processo de mercado segundo Kirzner (1997): a gestão empreendedora; a descoberta de novos conhecimentos e a promoção da competição. Fica a iniciativa privada inibida de sua capacidade criativa, coragem e esforço (KIRZNER, 1997), uma vez que se depara com as amarras de sua sociedade, com a empresa pública que deve seguir a legislação, tanto para compras como para gestão de pessoal. A livre iniciativa é então condição necessária para que a gestão do orçamento e sua aplicação em novos empreendimentos, tecnologias e soluções de problemas gerenciais possibilite a melhor alocação de recursos. Inibido o processo de mercado como um todo, fica limitada a seleção de planos acertados por parte dos gestores privados, que têm como consequência o impedimento da evolução de conhecimento sobre a gestão e investimentos no setor aeroportuário, conforme ensina Barbieri (2001).

Se os aeroportos tivessem sido integralmente privatizados, então a INFRAERO não teria se deparado com uma situação ainda pior, em relação à gestão orçamentária e de pessoal. Operando aeroportos deficitários e com o mesmo número de servidores, a estatal viu-se em dificuldades para a gestão operacional e de pessoal. A presença da empresa pública comprometeu, não somente o alcance dos objetivos da concessão, como também limitou a ação empreendedora dos gestores privados, a ampliação do conhecimento e a promoção da competição, já que a empresa pública estava sempre presente dos dois lados da mesa de negociação, tanto como sócia da empresa privada, como sendo a gestora de outros aeroportos brasileiros. 
É digno de nota o fato de Ludwig von Mises ter escrito seus textos sobre o intervencionismo estatal nos primeiros anos da década de 1940, apresentando os questionamentos que foram utilizados como guia para esta pesquisa, sobre um processo realizado setenta anos depois de seus escritos. Isso comprova o caráter atemporal do pensamento misesiano e da aplicabilidade de sua teoria à prática da gestão organizacional contemporânea. Recomenda-se que, em futuros trabalhos, os pesquisadores se debrucem sobre processos de desestatização, que possam ser realizados no Brasil nos diferentes segmentos, propondo encaminhamentos à luz dos preceitos da Escola Austríaca.

\section{Referências}

ANAC. AGÊNCIA NACIONAL DE AVIAÇÃO CIVIL. Concessões. Disponível em: https://www.anac.gov.br/ assuntos/paginas-tematicas/concessoes. Acesso em: 25 nov 2019.

Contrato de concessão para ampliação, manutenção e exploração do Aeroporto Internacional de Guraulhos. Brasília, DF, 2012.

ANGELI, Eduardo. Caminhos da Escola Austríaca: relação com ortodoxia, engajamento e produção de novo conhecimento. Nova Economia, v. 28, n. 2, p. 681-704.

ARBLASTER, Margaret; HOOPER, Paul. Light handed regulation - Can it play a role in the developing world? Transport Policy, v. 43, p. 32-41, 2015.

BARBIERI, Fábio. O Processo de Mercado na Escola Austríaca Moderna. São Paulo: FEA/USP, 2001.

BARBIERI, Fábio; FEIJÓ, Ricardo Luis Chaves. Metodologia do Pensamento Econômico: O Modo de Fazer Ciência dos Economistas. São Paulo: Editora Atlas, 2013.

BRASIL. Lei 8.666, de 21/06/1993. Regulamenta o art. 37, inciso XXI, da Constituição Federal: normas para licitações e contratos da Administração Pública e dá outras providências. Diário Oficial da União, Brasília, 1994. Disponível em: http://www.planalto.gov.br/ccivil_03/leis/L8666cons.htm. Acesso em: 20 set 2019.

BRASIL. Lei 8.112 de 11/12/1990. Dispõe sobre o regime jurídico dos servidores públicos civis da União, das autarquias e das fundações públicas federais. Diário Oficial da União, Brasília, 1990. Disponível em: http:// www.planalto.gov.br/ccivil_03/leis/L8112cons.htm. Acesso em: 20 set 2019.

CARRASCO, Vinícus; JOAQUIM, Gustavo; PINHO DE MELLO, João Manoel. Risco regulatório no Brasil: teoria e mensuração. In: CASTELAR, Armando Pinheiro; FRISCHTAK, Cláudio (Orgs.). Gargalos e soluções na infraestrutura de transportes. Rio de Janeiro: Editora FGV, 2014.

COOPER, Donald R.; SCHIDLER, Pamela S. Métodos de pesquisa em Administração. Porto Alegre: Bookman, 2003.

DI PIETRO, Maria Sylvia Zanella. Direito Administrativo. São Paulo: Atlas, 2004.

GILLEN, David. The evolution of airport ownership and governance. Journal of Air Transport Management. v. 17, p. 3-13, 2011.

GRAHAM, Anne. The objectives and outcomes of airport privatization. Research in Transportation Business \& Management, v., 1, p. 3-14, 2011.

HARISANKAR, K.; SREEPARVATHY, G. Rethinking Dispute Resolution in Public-Private Partnerships for Infrastructure Development in India. Journal of Infrastructure Development, v. 5, n. 1, p. 21-32, 2013. 
HAYEK, Friedrich August. Individualism \& Economic Order. Chicago: University of Chicago Press, 1948. Disponível em: http://www.library.fa.ru/files/Hayek-Individualism.pdf. Acesso em: 30 set 2019.

O Caminho da Servidão. São Paulo: Instituto Ludwig von Mises Brasil, 2010.

INFRAERO. Concessão de aeroportos. 2016. Disponível em: https://www.INFRAERO.gov.br/index.php/br/ transparencia/concessao.html. Acesso em: 20 set 2019.

KIRZNER, Israel. Entrepreneurial Discovery and the Competitive Market Process: An Austrian Approach. Journal of Economic Literature, v. 35, n.1, p. 60-85, 1997. Disponível em: https://econfaculty.gmu.edu/pboettke/ summer/summer\%20docs/kirzner1997.pdf. Acesso em: 30 set 2019.

LAKATOS, Eva Maria; MARCONI, Marina de Andrade. Técnicas de Pesquisa. São Paulo: Editora Atlas, $7^{a}$ Ed., 2010.

MANTIN, Benny. Airport complementarity: private vs. government ownership and welfare gravitation. Transportation Research, p. 381-388, 2012.

MISES, Ludwig von. Planning for freedom and the twelve other essays. South Holland: Libertarian Press, 1980. Disponível em: https://mises-edia.s3.amazonaws.com/Planning\%20for\%20Freedom\%20and\%20Twelve\%20 other\%20Essays\%20and\%20Addresses_2.pdf. Acesso em: 30 set 2019.

Ação Humana: Um Tratado de Economia. São Paulo: Instituto Ludwig von Mises, 2010a.

Intervencionismo: Uma Análise Econômica. São Paulo: Instituto Ludwig von Mises, 2010b.

O cálculo econômico sob o socialismo. São Paulo: Instituto Ludwig von Mises, 2012.

OUM, Tae; H., ADLER; Nicole.; YU, Chunyan. Privatization, corporatization, ownership forms and their effects on the performance of the world's major airports. Journal of Air Transport Management, v. 12, n. 3, p. 109-121, 2006.

Ownership forms matter for airport efficiency: A stochastic frontier investigation of worldwide airports. Journal of Urban Economics, v. 64, n. 2, p. 422-435, 2008.

PARANAÍBA, Adriano de Carvalho; BULHOES, Eliezé. Transportar é preciso: uma proposta liberal. São Paulo: LMV Editora, 2019.

PEREIRA NETO, Cio Mário da Silva et al. Pro-competition rules in airport privatization: international experience and the Brazilian case. Journal of Air Transport Management, v. 54, p. 9-16, 2016.

PPI. PROGRAMA DE PARCERIAS DE INVESTIMENTOS. $\mathbf{6}^{\mathbf{a}}$ Rodada de Concessões Aeroportuárias - Blocos Sul, Norte I e Central. Disponível em: https://www.ppi.gov.br/6-rodada-de-concessoes-aeroportuarias-blocossul-norte-i-e-central. Acesso em: 20 set 2019.

SCOTTI, Davide et al. The impact of airport competition on technical efficiency: A Stochastic Frontier Analysis Applied to Italian Airport. Journal of Air Transport Management, v. 22, p. 9-15, 2012.

SILVA, Elisangela Aparecida Machado da; ARAÚJO SOBRINHO, Fernando Luiz; FORTES, José Augusto Abreu Sá. A importância geoestratégica do Aeroporto Internacional de Brasília no desenvolvimento do turismo regional. Caderno Virtual de Turismo, Rio de Janeiro, v. 15, n. 3, p. 303-316, 2015.

SIMIONATO, Luiza Reis; STAMM JÚNIOR, Mário César. Movimentação de carga internacional em aeroportos brasileiros. Congresso Técnico Científico da Engenharia e da Agronomia (CONTECC/2016), 29/08 a 01/09/2016, Foz do Iguaçu, PR. 
TCU. TRIBUNAL DE CONTAS DA UNIÃO. Processo no. TC 024.918/2014-8. Relatório de auditoria operacional. Qualidade de serviço nos aeroportos brasileiros, 2014. Disponível em: www.tcu.gov.br/Consultas/Juris/Docs/ judoc/Acord/.../AC_2210_35_15_P.doc. Acesso em: 20 set 2019.

RECEBIDO EM: 12/11/2019

APROVADO EM: 12/11/2019 